\title{
Entre bolhas: uma análise de formação de redes no Twitter no contexto da pandemia do novo coronavírus no Brasil
}

\author{
Priscila KALINKE ${ }^{1}$ \\ Anderson Alves da ROCHA ${ }^{2}$ \\ Karol Natasha Lourenço CASTANHEIRA ${ }^{3}$
}

Resumo:

Este artigo tem como objetivo investigar os movimentos que aconteceram no Twitter entre apoiadores e críticos ao governo do presidente Jair Bolsonaro em relação ao marco das 100 mil mortes no Brasil relacionadas à Covid-19, por meio de hashtags. Como suporte metodológico, o trabalho recorre à análise de redes para mídias sociais, nas quais destacam-se os principais indicadores a serem analisados: Indegree; PageRank e Centralidade Eigenvector. Conclui-se que os clusters formados entre opositores e apoiadores do governo não se divergem internamente, porém não chegam a efetivar conexões entre si, estabelecendo apenas interações filtradas em bolhas, nas quais acabam por contribuir para uma esfera pública cujas opiniões se reverberam em câmaras de eco, diluindo o diálogo entre o contraditório como princípio importante para a democracia.

Palavras-chave: Câmaras de eco. Topologia da rede. Esfera pública. Covid-19.

\section{Between bubbles: an analysis of network formation on Twitter in the context of the pandemic of the new coronavirus in Brazil}

\begin{abstract}
:
This article aims to investigate the movements that happened on Twitter between supporters and critics of government of President Jair Bolsonaro's government related to the mark of 100,000 deaths in Brazil related to Covid-19 through hashtags. As a methodological support, the work uses analysis of networks for social media, in which the main indicators to be analyzed are highlighted: Indegree; Betweenness; PageRank and Eigenvector Centrality. It was concluded that the clusters formed between opponents and supporters of the government do not diverge internally, however, they do not actually establish connections between themselves, establishing only interactions filtered in bubbles, in which they end up contributing to a public sphere whose opinions reverberate in chambers of public opinion. echo, diluting the dialogue between the adversary as an important principle for democracy.
\end{abstract}

Keywords: Echo chambers. Network topology. Public sphere. Covid-19.

\section{Entre burbujas: un análisis de la formación de redes en Twitter en el contexto de la pandemia del nuevo coronavirus en Brasil}

\section{Resumen:}

Este artículo tiene como objetivo investigar los movimientos que sucedieron en Twitter entre simpatizantes y críticos del gobierno del presidente Jair Bolsonaro frente a 100.000 muertes en Brasil relacionadas con Covid-19 a través de hashtags. Como suporte metodológico, o trabajo usa análisis de redes para redes sociales, en el que destacan los principales indicadores a analizar: Indegree; Intermediación; PageRank y centralidad de vector propio. Se concluyó que los clusters formados entre opositores y simpatizantes del gobierno no divergen

\footnotetext{
${ }^{1}$ Doutora em Comunicação, Universidade do Estado de Minas Gerais. E-mail: priscila.kalinke@uemg.br.

${ }^{2}$ Doutor em Comunicação, Universidade do Estado de Minas Gerais. E-mail: anderson.alves.rocha@uemg.br.

${ }^{3}$ Doutora em Comunicação, Universidade do Estado de Minas Gerais. E-mail: karol.castanheira@uemg.br.
} 
internamente, sin embargo, en realidad no establecen conexiones entre sí, estableciendo solo interacciones filtradas en burbujas, en las que terminan contribuyendo a una esfera pública cuyas opiniones reverberan. en las cámaras de opinión pública, eco, diluyendo el diálogo entre el adversario como principio importante para la democracia.

Palabras clave: Cámaras de eco. Topología de la red. Esfera pública. COVID-19.

\section{Introdução}

Em 8 de agosto de 2020 o Brasil alcançou o número de 100 mil mortos pela pandemia de Covid-19 (BRASIL..., 2020). A marca expressiva de pessoas mortas pela doença gerou repercussão no país e no mundo. Sua comunicação por meios tradicionais de divulgação da informação se deu em paralelo com as novas ferramentas digitais de divulgação, bem como a repercussão do fato.

Durante décadas os meios de comunicação massivos tiveram a hegemonia no controle da informação, por meio do jornalismo. Mesmo levando em conta os diversos paradigmas de análise teórica nos estudos da comunicação, os sistemas de difusão da informação de interesse público sempre obedeceram a um padrão vertical de distribuição. A circulação da notícia iniciava sua trajetória centralizada por grandes produtores e somente após sua divulgação ela passava a circular horizontalmente.

Porém, no início do século XXI essa relação começou a se transformar. O fenômeno denominado "cultura da convergência" (JENKINS, 2009) observou a transformação da relação entre produtores e consumidores da informação. A internet passou a prover um meio de conexão direta entre os receptores da comunicação e a propiciar um esquema de produtor/receptor simultâneo. "Convergência e conexão são o que impulsiona a mídia agora e aquilo que assegura que a mídia seja importante em todos os níveis, desde o mais micro e hiperlocal, até o mais macro" (JENKINS; KALINKE; ROCHA, 2015, p. 216).

Assim, este artigo tem por finalidade principal analisar as redes formadas pelo Twitter no dia em que foram registradas 100 mil mortes pelo novo coronavírus no Brasil, a partir das principais hashtags utilizadas nessa mídia social. Em especial, entender os influenciadores mais expressivos nesse processo e observar se os veículos de comunicação podem ser incluídos nesse rol de articuladores relevantes da rede. Para subsidiar a interpretação dos dados fornecidos pelas redes, foi necessário entender as relações entre interações mediadas por tecnologias digitais, midiatização e formação de opinião na esfera pública online.

Os processos interacionais, a produção de redes emergentes e filiativas, os laços dialógicos ou associativos trabalhados de forma bastante descritivas em Redes Sociais na 
Internet (RECUERO, 2009) deram subsídios conceituais para investigar o que seriam relações em redes sociais. Mas somente entender "o que está sendo produzido" no Twitter não nos bastava, portanto, passamos a discutir “o que está acontecendo". Nesse sentido, nos pareceu pujante estabelecer conexões com a ideia de esfera pública, enquanto espaço de produção da opinião pública e do debate político acerca das questões de interesse público (HABERMAS, 1984, 1997).

Interrogamo-nos, portanto, se ao desvendar "o que está acontecendo aqui” encontraríamos também câmaras de eco (SUNSTEIN, 2001) que ressoam apenas aquilo que agrada ao usuário, fechando as opiniões em um microcosmo da esfera pública (EP), em um assunto de gravidade letal que é o novo coronavírus.

\section{Breve histórico da Covid-19}

A partir de janeiro de 2020 o mundo passou a acompanhar as notícias de uma doença que se espalhava de Wuhan (China) e amaçava uma onda de contágios que poderia comprometer o mundo: o vírus nomeado SARS-CoV-2, popularmente chamado de "novo coronavírus". A província chinesa, primeiro epicentro da doença (que foi nomeada oficialmente de COVID-19, sigla para Corona Virus Disease 2019), já tinha matado 17 pessoas e contaminado 400 no dia 23 de janeiro de 2020. Nesse mesmo dia, o diretor geral da Organização Mundial de Saúde (OMS), Tedros Adhanom ${ }^{4}$ convocou um comitê de emergência de especialistas independentes com o intuito de verificar a necessidade de declarar uma emergência de saúde pública de alcance internacional (AS AÇÕES..., 2020).

O Brasil registrou a primeira confirmação da doença em território nacional no dia 26 de fevereiro, em São Paulo. No dia 12 de março foi confirmada a primeira morte pela doença no país. As autoridades de saúde preparavam medidas para enfrentar a doença que havia sido declarada como pandemia global um dia antes pela OMS (WHO Director's-General..., 2020).

A partir do dia 20 de março grande parte dos estados brasileiros já haviam implementado regras de isolamento social, restrição de circulação de pessoas, fechamento de estabelecimentos comerciais não essenciais e instituições de ensino. Após o mês de maio, o país experimentou um aumento exponencial do número de casos (Figura 01) e passou a ser considerado o novo epicentro da pandemia, ultrapassando a marca de 1000 mortes diária entre o dia 21 e 22 de maio de 2020. "Com 1.188 novas mortes por coronavírus nas 24 horas entre

\footnotetext{
${ }^{4}$ Tedros Adhanom Ghebreyesus (1955 - ) é um biólogo e doutor em saúde pública etíope, que atuou como ministro da saúde na Etiópia de 2005 a 2012 e foi eleito como presidente da OMS pela Assembleia Mundial da Saúde em 2017. Disponível em: https://www.who.int/director-general/biography.
} 
quarta e quinta, segundo dados do Ministério da Saúde, o Brasil bateu novo recorde de mortes diárias e passou de 20 mil óbitos" (PINTO, 2020).

Figura 01 - Progressão dos casos de Coronavírus no Brasil

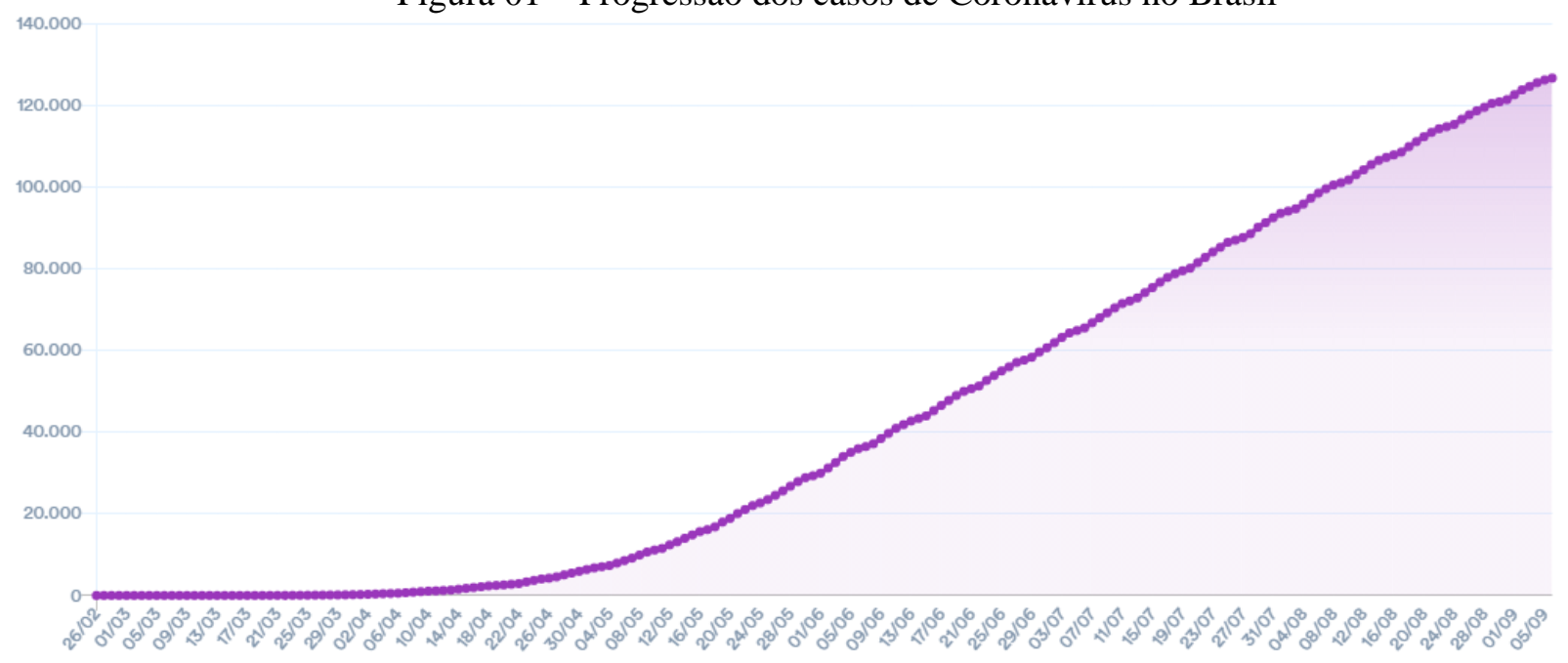

Fonte: Ministério da Saúde (CORONAVÍRUS BRASIL, 2020)

O número de mortes passou a permanecer acima de 1000 pessoas por dia (segundo a média móvel de mortes) e em 20 de junho o Brasil alcançou a marca de 50 mil pessoas mortas pela Covid-19, segundo dados do Ministério da Saúde e do Consórcio ${ }^{5}$ formado por veículos de imprensa para a contagem de casos da doença do país (VEÍCULOS..., 2020).

As medidas de isolamento social no Brasil passaram a ser questionadas por políticos e pela população em geral conforme os casos avançavam no país, porém, o número de mortos e contaminados não mostrava tendência de queda. Em 08 de agosto de 2018, um sábado, o Brasil registrou a marca de 100 mil mortos pela doença, sendo naquele momento o segundo maior número de mortes pela doença no mundo (BRASIL..., 2020).

\section{Redes e esfera pública}

A produção tecnológica a partir de demandas sociais e investimento do capital fez surgir ao longo da história da comunicação uma profusão de vertentes teórico-metodológico sobre os usos (BLUMER; ELIHU, 1974), efeitos (LASSWELL, [1948] 1987; LAZARSFELD; MERTON, [1948] 1987), cultura (HALL, 2006) e processos (MARTÍNBARBERO, 1997) entre os meios de comunicação e a sociedade. Este cenário foi

\footnotetext{
${ }^{5}$ No mês de junho as redações do G1, O Globo, Extra, Estado de S. Paulo, Folha de S. Paulo e UOL passaram a buscar os dados diretamente das secretarias de Saúde e divulgar em conjunto os números sobre mortes e contaminados, em razão das limitações impostas pelo Ministério da Saúde.
} 
intensificado com o desenvolvimento da microeletrônica em 1950, que deu subsídio para a configuração das tecnologias digitais, recodificando o mundo social.

Estudioso da sociedade em rede, Castells (2002a) aponta para uma mudança de paradigma, no qual o sistema produtivo, que, até então, era a força motriz da sociedade, definida por meio da força e das relações existentes a partir do trabalho, deixa de ser a categoria central para o que ele define como sistema informacional. A sociedade passa a ser vista, então, como uma rede multicultural e interdependente, valorando mais as identidades sociais (cultura) e não as classes sociais (sistema produtivo). Para Castells (2002b), esta sociedade informacional é uma forma específica de organização social que tem a informação como fonte de produtividade e poder, em que conhecimentos e informações fazem parte de um "círculo virtuoso" em que o uso gera inovação.

Ao propor o conceito de Sociedade Informacional, vale ressaltar que Castells (2002a), na visão de Di Felice (2012, p. 33), estava, ainda nesse primeiro livro, a observar a aceleração da informática a partir da década de 1970 e que a lógica dessa rede não escapava aos processos sociais dominantes, mas que também intensificava "o 'espaço de fluxos', enquanto lógica espacial das redes digitais, e o 'espaço de lugares' da nossa experiência histórica de organização espacial e de identidade".

A configuração de uma sociedade em rede, apesar de compreender os diversos gargalos de inclusão, que coloca atores, grupos sociais e até mesmo países em uma posição periférica, fez surgir um novo modelo comunicativo que se destoa de todos os outros construídos, até então, para fazer surgir o modelo todos-todos, no qual o receptor é exponencialmente o emissor, como propõe a ideia de rede (CASTELLS, 2002a). Este modelo suscitou ainda mais o debate acerca da participação cidadã na esfera pública em sociedades democráticas (BASTOS, 2012), além de refletir sobre o próprio modo de funcionamento proveniente das redes sociais mediadas por tecnologias digitais.

Isto fez emergir no Brasil diversas pesquisas no campo digital. Para este artigo, interessa-nos em particular os estudos de Recuero (2009) de interação social, a fim de verificar quais redes estão sendo formadas no Twitter. Segundo Recuero (2009), alguns atores acabam por estabelecer mais conexões do que outros: Isto se dá por diversos motivos: emergentes (que podem expressar identificação e laços sociais), associação (sentimento de pertencimento), e até mesmo por determinados valores como visibilidade, popularidade, autoridade e reputação. 
Figura 02 - Elementos de redes sociais na internet

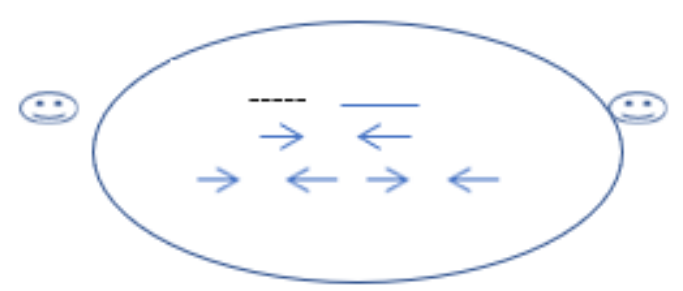

Nó ou ator social: tem a iniciativa da comunicação e alimenta a rede com informação.

Laços sociais fracos: efetiva conexões entre os atores envolvidos na interação, se caracteriza por relaç̃os esparsas, que não traduzem proximidade ou intimidade.

Laços sociais fracos: efetiva conexões entre os atores envolvidos na interação, se caracterizam pela intimidade, proximidade e intensidade emocional. $\rightarrow \leftarrow$ Interação: ação que tem um reflexo comunicativo e social entre indivíduos e seus pares.

$\rightarrow \leftarrow$ Relações: conjunto de interações $\rightarrow \leftarrow$

Conexões: conjunto de laços, interações e relações sócias.

Fonte: Adaptação (RECUERO, 2009).

Apesar do entendimento da topologia das redes e de verificar a formação de clusters, interações e relações em um marco de registro de 100 mil mortos no Brasil ocasionado pela pandemia da Covid-19, outra questão nos foi muito premente, que é a formação da opinião pública no Twitter acerca desse tema, caracterizando-o enquanto espaço de esfera pública online.

A democracia, para Habermas (1984), se funda no entendimento entre as pessoas, que poderia se dar mediante o conflito e a divergência de opiniões, salutares no espaço democrático, mas que teriam por meio do uso do argumento racional a condição para o agir comunicativo. Sunstein (2001) se aproxima do pensamento habermasiano, a fim de problematizar os aspectos de deliberação em um regime democrático. $\mathrm{O}$ autor defende um argumento central e antigo, que é a necessidade em manter no espaço público uma multiplicidade de visões e perspectivas, que ultrapassem os interesses individuais, como condição essencial a evitar os extremismos. A proposta desse indicativo de solução veio após Sunstein (2001) identificar por meio de estudos de diversas práticas sociais de consumo e da 
produção limitante de uma cidadania participativa, o que ele denominou de Câmara de Ecos.

Bastos (2012) já apontava para algumas singularidades da circulação de informação das redes sociais como: ruptura da linearidade do processo comunicativo, descentralização da produção de informação, participação (reativa ou mútua), mas destacamos o aspecto de seleção dos usuários. Esta aparente autonomia do usuário é também pré-determinada pelo uso de algoritmos e cookies que reforçam a publicização e a visibilidade de informações no perfil da rede social a partir de conteúdos preferenciais com os gostos e ideias do cidadão, ação identificada como filtros-bolha (PARISER, 2011).

A contradição fundamental para a esfera pública em uma sociedade democrática passa a ser, então, invisibilizada, porque "essas bolhas tendem a isolar os atores dentro de grupos onde apenas alguns tipos de informação circulam, criando uma percepção falsa de EP (onde 'todos' falam) e de opinião pública (onde a 'maioria' concorda)" (RECUERO; ZAGO; SOARES, 2017, p. 2).

\section{Procedimentos metodológicos}

Para avançarmos na análise dos dados coletados no Twitter em 08 de agosto de 2020, dia em que - segundo o boletim do consórcio de veículos de imprensa (BRASIL..., 2020) - o Brasil chegou ao número de 100 mil mortos pela pandemia de Covid-19, é preciso apresentar os aspectos metodológicos propostos para essa análise. As raízes da teoria dos grafos emergem a partir do estudo do matemático Leonhard Euler, o qual em 1736 tentou resolver o enigma das pontes de Königsberg, cidade construída parcialmente sobre duas ilhas (RECUERO; BASTOS; ZAGO, 2018). O enigma era: é possível passar por todas as pontes, sem repetir nenhuma, e voltar ao início do trajeto? A resposta foi não, ou seja, era impossível não repetir em virtude do número das pontes. Na figura abaixo (Figura 03), o grafo mostra que as pontes eram representadas pelas conexões (arestas) e a cidade, pelos nós. 
Figura 03 - Pontes de Königsberg
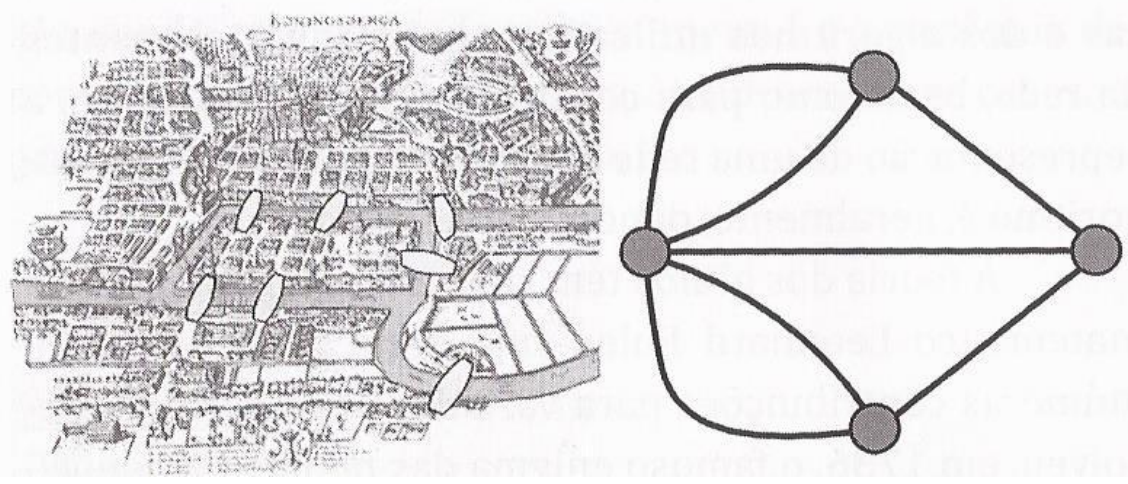

Fonte: Recuero, Bastos, Zago (2018, p. 48).

Embora a origem seja matemática, esta matriz pode servir de representação das relações de uma sociedade, que foi o estudo de Jacob Moreno, em 1934, que intitulou a pesquisa como "estudo sociométrico" (RECUERO; BASTOS; ZAGO, 2018). É evidente que diante da explosão de meios de conexão digitais que temos na atualidade (JENKINS; GREEN; FORD, 2014), essas pesquisas eclodem como importante ferramenta para analisar os fluxos comunicacionais, sociais e discursivos nas mídias sociais, quando sabemos que os conteúdos midiáticos permeiam para além dos meios tradicionais e circulam na cultura, como evidencia Braga (2012) ao tratar da midiatização.

A partir da possibilidade de registro das interações nos sites de redes sociais, bem como a organização e visualização por meio de softwares, a análise poderá ser desenvolvida com auxílio de algumas informações retiradas dos próprios programas (Gephi, por exemplo) e o suporte fundamental da análise contextual do tema, o qual está sendo investigado. Esta pesquisa versará sobre as hashtags relacionadas às vítimas da COVID-19 e buscaremos entender os principais influenciadores na rede, atentando-nos aos veículos de imprensa, a fim de entender qual é o papel dos meios de informação junto à temática, no Twitter.

Para atender a este objetivo, separamos alguns indicadores na Análise de Redes Sociais (ARS) que podem nos auxiliar a compreender os conectores mais potentes, que conseguem dinamizar e expandir as relações acerca do assunto debatido. Neste ponto, destacamos os principais indicadores a serem analisados: Indegree (grau de entrada); Betweenness (Grau de Intermediação); PageRank e Centralidade Eigenvector (centralidade de autovetor). Para ficar mais claro, a seguir vamos explicar a importância de cada um para expressar a relevância do nó na rede.

Indegree é a medida de conexões que o nó recebe (RECUERO, 2014), o que significa 
dizer que o ator da rede que recebe muitas menções ou seu conteúdo é muito retweetado, por exemplo, possivelmente terá um alto valor no indicador indegree. Esse resultado pode mensurar, portanto, quão significativo o nó é para a construção de toda a matriz formada.

Grau de intermediação (Betweenness) apresenta quantas vezes o nó se torna "ponte" a diferentes grupos de nós (RECUERO, 2014). Um alto valor no grau de intermediação pode sugerir que o nó conecta uma variedade de setores da rede e sua relevância para manter a rede unida. Assim, contribui para que a informação flua pela rede (MORALES; ALENS, 2019). Esse ator da rede é importante para entender o processo de diálogo entre diferentes grupos de nós, sobretudo se esse diálogo acontece por afinidades ou disputas de narrativas.

PageRank trata especialmente de sua influência dos nós em virtude de suas conexões, ou seja, a qualidade das conexões possibilita a mensuração de sua importância. Recuero (2014, p. 66) afirma que o intuito é observar quais as chances de "um ator seguindo links de forma aleatória terá de chegar na 'página' do nó, ranqueando esses nós com conexões 'melhores' de forma mais alta". Nesta mesma intenção de investigar a influência do nó na rede, a medida de Centralidade de Autovetor (BONACICH, 1987) também avalia a sua relevância com base na importância de seus vizinhos, por meio de suas relações diretas e indiretas. Ou seja, PageRank e Centralidade de Autovetor são bons indicadores de influenciadores na rede analisada, com base na qualidade de suas conexões com outros atores.

Para a coleta e visualização dos dados, foi utilizado o software Gephi a partir de hashtags que tinham relação às vítimas fatais da COVID-19, no Twitter, no Brasil, no dia em que o país atingiu o registro de 100 mil mortes causadas pela doença. Buscamos coletar hashtags criadas tanto de apoiadores como de críticos ao governo de Jair Bolsonaro, a fim de entender quem são os principais articuladores na formação das redes com estes elementos. No decorrer da análise será explicitado melhor quais as hashtags utilizadas entraram nos tranding topics do Twitter no dia 08 de agosto de 2020, no Brasil.

\section{Análise dos dados}

A seguir serão apresentadas as três etapas de coleta de dados realizadas no dia 08 de agosto de 2020, a partir de algumas hashtags que entraram nos tranding topics do Twitter, conforme mencionado na metodologia. Para observar os movimentos que aconteceram na plataforma entre apoiadores e críticos ao governo Bolsonaro quanto às 100 mil mortes no Brasil relacionadas à Covid-19, priorizamos: a) uma primeira coleta com hashtags contra e a 
favor à política do governo, buscando os termos Hidroxicloroquina e \#Bolsonaro100mil; b) um segundo momento com a hashtag \#Bolsonarotemrazao, utilizada pelos apoiadores do governo; c) o último \#Bolsonaro100mil, empregada pelos críticos à política do governo brasileiro. Durante todo o dia houve uma disputa entre as narrativas. Os argumentos dos que amparavam Bolsonaro era que a Hidroxicloroquina poderia ter evitado as mortes e que a responsabilidade incidia sobre os governadores e prefeitos. Já os críticos ao governo reforçavam que o presidente tinha a responsabilidade, por não apoiar as medidas de contenção do vírus e os protocolos sugeridos pela Organização Mundial da Saúde, privilegiando a economia em detrimento à saúde da população.

Tabela 01 - Resultados das hashtags Hidroxicloroquina \#Bolsonaro100mil, 08/08/20, 12h-13h

\begin{tabular}{|c|c|c|c|c|}
\hline & Indegree & PageRank & Eigenvector & Betweenness. \\
\hline $1^{\circ}$ & @marcelofreixo & (@) marcelofreixo & (@) marcelofreixo & @00paulocesari \\
\hline $2^{\circ}$ & @cinefilo_k & @cinefilo_k & @cinefilo_k & @safocerdeira171 \\
\hline $3^{\circ}$ & @samiabomfim & @arthurweint & @samiabomfim & @peixeixperto \\
\hline $4^{0}$ & (a) arthurweint & @reportersalles & $@ 00$ paulocesari & @_babby \\
\hline $5^{\circ}$ & @aguiaredil & (a) aguiaredil & @deusa_hela_. & $@$ walterkovacs 93 \\
\hline $6^{\circ}$ & @allanldsantos & @allanldsantos & @edinhopg12 & @1olaescreva \\
\hline $7^{\circ}$ & $@$ midianinja & @)samiabomfim & @arthurweint & @andreluis022 \\
\hline $8^{\circ}$ & @karlmarxis & @jairbolsonaro & @doutorpandego & @deusa_hela_ \\
\hline $9^{\circ}$ & @douglasgarcia & @bbcbrasil & @amyzinha95_ & (a) nevesclaudia213 \\
\hline $10^{\circ}$ & @thatihp & @karlmarxis & @marguimara & @verdade_verdad \\
\hline
\end{tabular}

Fonte: Autores da pesquisa.

A Tabela 01 mostra os valores relativos aos termos Hidroxicloroquina e \#Bolsonaro100mil, que foram utilizados pelos dois grupos, apoiadores e críticos ao governo, respectivamente. Quando analisamos o grau de entrada dos perfis, observamos que quem obteve maior indegree foi @marcelofreixo, conta oficial de Marcelo Freixo, deputado federal pelo Partido Socialismo e Liberdade (PSOL) do Rio de Janeiro, que recebeu 608 conexões mediante citações, retweets, menções. Além do deputado, os dois próximos com maior número de conexões são@cinefilo_k e @ samiabomfim, ambos perfis de orientação mais à esquerda, inclusive Sâmia Bomfim, que também é deputada federal pelo PSOL.

Como os dados também foram coletados mediante a menção ao termo Hidroxicloroquina, era evidente que perfis que se declararam apoiadores ao presidente Jair 
Bolsonaro também apareceriam entre os maiores indegrees, como, por exemplo, @arthurweint, @aguiaredil, @allanldsantos e @douglasgarcia. Entre estes, incluem-se Arthur Weintraub, assessor especial do presidente Jair Bolsonaro; Allan dos Santos, blogueiro bolsonarista e um dos investigados no inquérito das fake news (Investigado pelo STF..., 2020) no Supremo Tribunal Federal; e Douglas Garcia, deputado estadual do Partido Trabalhista Brasileiro (PTB) de São Paulo e representante do Movimento Conservador (THOMAZ, 2019).

É possível observar que muitos destes perfis se repetem nos indicadores PageRank e Eigenvector, ou seja, estes nós são considerados relevantes na rede em razão das suas conexões com outros nós também importantes. De modo geral, podemos atribuir como principal articulador da rede o deputado federal Marcelo Freixo, conforme mostram os dados. Entre os veículos de imprensa, observamos que foram mensurados (Indegree e PageRank) de forma acentuada na rede apenas: a) a Mídia Ninja (Jornalismo Independente e Narrativas de Ação), que ganhou notoriedade na cobertura dos protestos durante as manifestações de junho de 2013, no Brasil, e possui um diálogo com grupos de mídia cidadã e midiativistas internacionais (MÍDIA NINJA, s.d.); e b) BBC Brasil, veículo de jornalismo que atua no país há mais de 80 anos (BBC..., 2009, 2011).

Ainda destacamos o perfil do presidente Jair Bolsonaro no PageRank, em razão sobretudo das menções feitas pelos críticos à sua gestão durante a pandemia no Brasil. Em decorrência dessas menções feitas pelos opositores ao presidente, é possível observar que o nome de Jair Bolsonaro aparece no cluster roxo do grafo (Figura 04), que é formado justamente, na maioria, pelos perfis com posicionamento mais à esquerda, assim como o agrupamento azul. Em verde, são majoritariamente as contas do Twitter que se declaram favoráveis ao governo, o que pode ser percebido pelo maior distanciamento em relação às demais comunidades.

Ainda ao analisar a Tabela 01, verificamos que as contas do Twitter que mais têm interconexões entre clusters (Betweenness) se tratam, em sua maioria, de opositores ao presidente, ou seja, estes são as principais pontes entre as diferentes comunidades. Contudo, ao analisar o laboratório de dados do Gephi, observa-se que estas conexões são essencialmente entre os grupos que também são críticos ao governo, ou seja, não necessariamente há um diálogo entre posicionamentos distintos. 
Figura 04 - Grafo dos termos Hidroxicloroquina \#Bolsonaro100mil no Twitter 12h-13h (08/08/20)

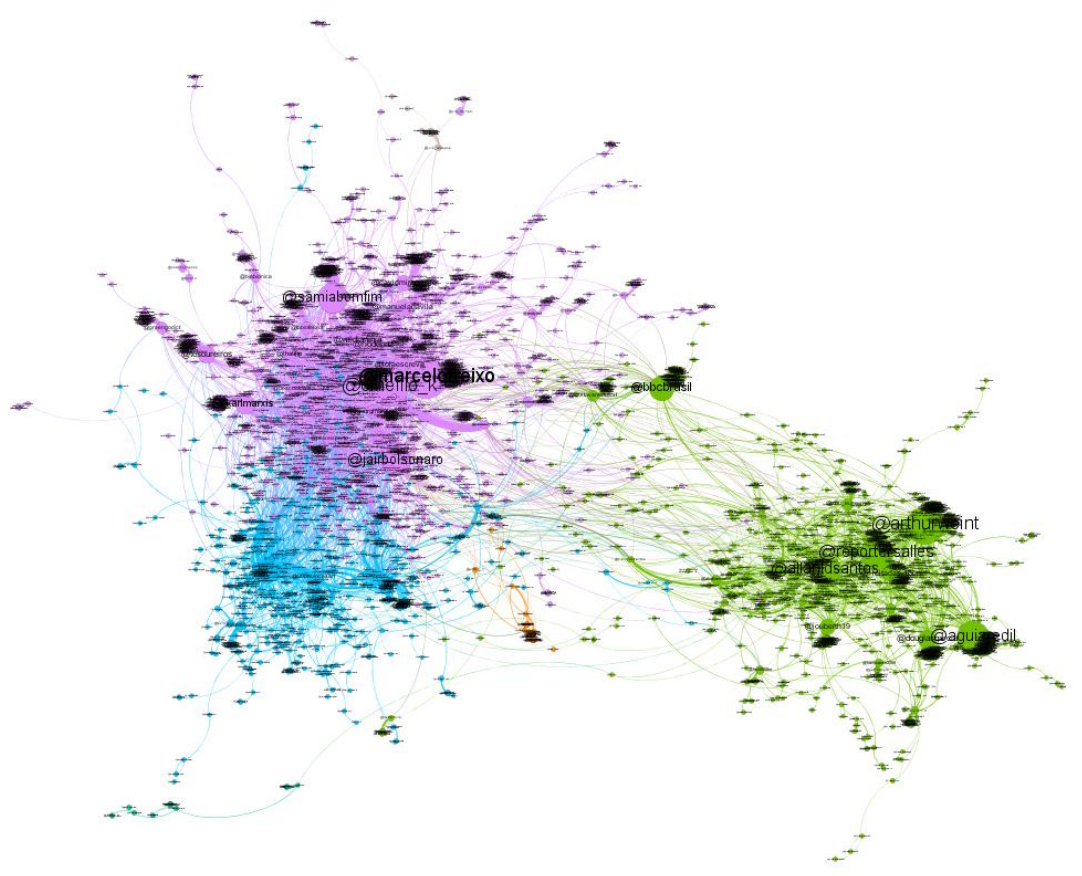

Fonte: Autores da pesquisa.

Tabela 02 - Resultados da hashtag \#Bolsonarotemrazao, 08/08/20, 19h20-20h20

$\begin{array}{lllll} & \text { Indegree } & \text { PageRank } & \text { Eigenvector } & \text { Betweenness } \\ \mathbf{1}^{\circ} & @ \text { profpaulamarisa } & @ \text { jouberth19 } & @ \text { jouberth19 } & @ \text { anaamvs_sanches } \\ \mathbf{2}^{\circ} & @ \text { jouberth19 } & @ \text { profpaulamarisa } & @ \text { profpaulamarisa } & @ \text { ppreacafla2 } \\ \mathbf{3}^{\circ} & @ \text { carlosjordy } & @ \text { carlosjordy } & @ \text { henriolliveira } & @ \text { xicomadruga } \\ \mathbf{4}^{\circ} & @ \text { lbonoro2 } & @ \text { gaycombolsonaro } & @ \text { lbonoro2 } & @ \text { hilma68946015 } \\ \mathbf{5}^{\circ} & @ \text { henriolliveira } & @ \text { jairbolsonaro } & @ \text { carlosjordy } & @ \text { coxa1313 } \\ \mathbf{6}^{\circ} & @ \text { brunaobarreto } & @ \text { lhmandetta } & @ \text { brunaobarreto } & @ 5 \text { zt1nm6mmokyh99 } \\ 7^{\circ} & @ \text { colunapatriota } & @ \text { lbonoro2 } & @ \text { vlogdolisboa } & @ \text { mariluciferraz } \\ \mathbf{8}^{\circ} & @ \text { vlogdolisboa } & @ \text { henriolliveira } & @ \text { jairbolsonaro } & @ \text { luciano94703692 } \\ \mathbf{9}^{\circ} & @ \text { gaycombolsonaro } & @ \text { carlosbolsonaro } & @ \text { colunapatriota } & @ \text { miriamtaokei100 } \\ \mathbf{1 0}^{\circ} & @ \text { jairbolsonaro } & @ \text { luislacombereal } & @ \text { gaycombolsonaro } & @ \text { bastosjusmari }\end{array}$

Fonte: Autores da pesquisa.

$\mathrm{Na}$ sequência, também coletamos dados separadamente, isto é, uma coleta com \#Bolsonarotemrazao (Tabela 02 e Figura 05) e outra com \#Bolsonaro100mil (Tabela 03 e Figura 06), as quais, respectivamente, foram utilizadas por apoiadores e críticos à gestão de Bolsonaro no período da pandemia de coronavírus no Brasil. A primeira análise versará sobre 
\#Bolsonarotemrazao e, em seguida, \#Bolsonaro100mil. Como nos dois casos a coleta se deu com hashtag utilizada por públicos mais homogêneos, percebe-se que os grafos são mais coesos (Figura 05 e Figura 06), com poucos clusters distantes, diferentemente da anterior, em que havia uma disputa de narrativas entre seus integrantes (Figura 04).

Na Tabela 02 observamos os dados referentes à \#Bolsonarotemrazao, hashtag usada pelos apoiadores do presidente cujo objetivo era reforçar que a política de governo de Jair Bolsonaro estava correta, especialmente em relação à gestão econômica na pandemia e ao uso de medicamentos como a hidroxicloroquina, além de criticar os governos e prefeitos, que contrariavam as orientações do presidente. Neste sentido, em grande medida atribuíam os problemas econômicos e as mortes por COVID-19 no Brasil aos gestores estaduais e municipais.

A primeira coluna dos indicativos da Tabela 02 mostra o grau de entrada de conexões. Com maior valor indegree, o perfil da professora Paula Marisa - @ profpaulamarisa - conta com mais de 250 mil seguidores ${ }^{6}$ e os principais conteúdos divulgados nessa conta do Twitter versam sobre pautas conservadoras e vinculadas à extrema direita. Além dessa plataforma, ela tem um canal no Youtube com mais de 500 mil inscritos e posicionando-se como "o maior canal conservador do sul do país”. Em seguida, @jouberth19, que recebeu 646 conexões, se autointitula "cristão, conservador e patriota" na conta do Twitter. No total, o perfil de Jouberth Souza tem 129 mil seguidores e também divulga conteúdos de apoio aos presidentes de extrema direita do Brasil e dos Estados Unidos. Na sequência, a conta do deputado federal Carlos Jordy (PSL-RJ), que é um dos líderes de Jair Bolsonaro no congresso, foi a mais conectada pelos demais nós da rede.

Os três perfis mencionados no parágrafo anterior também se mostram pertinentes nos dados apresentados pelos indicadores PageRank e Eigenvector, ou seja, esses nós estão conectados com outros nós também importantes, ampliando sua relevância. Os dados também revelam que não há veículos de imprensa, somente comentaristas de blogs pessoais alinhados à extrema direita. Como já citado, o grafo não apresenta comunidades distantes da parte mais central (Figura 04), pois geralmente são membros mais coesos, que têm linhas de pensamento mais próximas. O perfil @anaamvs_sanches apresenta o maior número de conexões entre diferentes clusters (Betweenness), mas o diálogo permanece entre os pares, sem permitir debates com diferentes ideias. É interessante observar que apenas alguns nós se distanciam do centro a partir da conexão com o perfil @gaycombolsonaro, em virtude do debate entre

\footnotetext{
${ }^{6}$ Visualizado em 25 de agosto de 2020.
} 
determinados atores da rede sobre o conflito que envolve as pautas LGBTQI+ e a gestão de Jair Bolsonaro.

Figura 05 - Grafo da hashtag \#Bolsonarotemrazao no Twitter 19h20-20h19 (08/08/20)

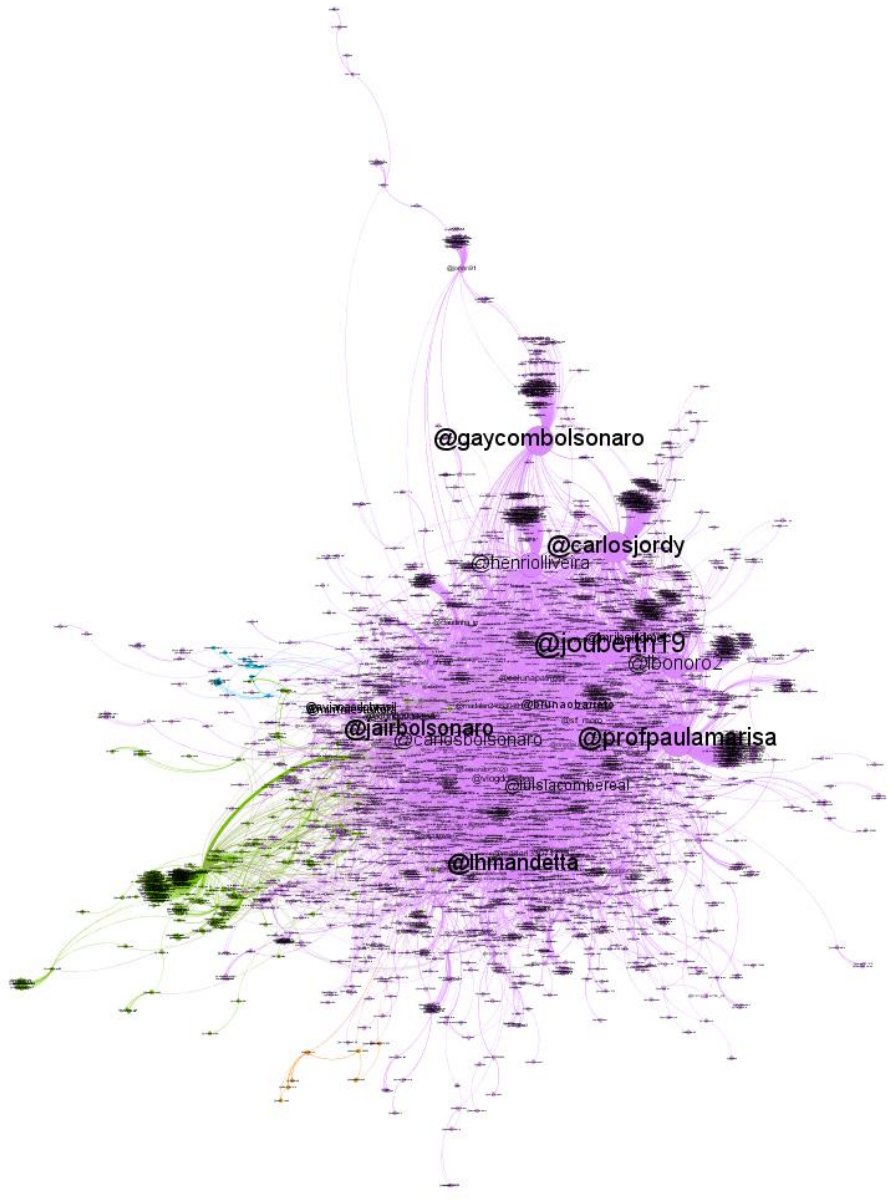

Fonte: Autores da pesquisa.

Tabela 03 - Resultados da hashtag \#Bolsonaro100mil, 08/08/20, 20h25-21h25

\begin{tabular}{|c|c|c|c|c|}
\hline & Indegree & PageRank & Eigenvector & Betweenness \\
\hline $1^{\circ}$ & @reinaldoazevedo & @ reinaldoazevedo & @ reinaldoazevedo & @1olaescreva \\
\hline $2^{\circ}$ & @marcelofreixo & @alexaguiarpoa & @marcelofreixo & @juballmoyses \\
\hline $3^{\circ}$ & @alexaguiarpoa & (@)marcelofreixo & @alexaguiarpoa & @leilaborgesa \\
\hline $4^{0}$ & (@)alessandromolon & (a) alessandromolon & (@)alessandromolon & $@$ pablitoinsegna \\
\hline $5^{\circ}$ & @guilhermeboulos & @manueladavila & @guilhermeboulos & (@)senadorhumberto \\
\hline $6^{\circ}$ & $@$ manueladavila & (a) guilhermeboulos & @manueladavila & @izabellula \\
\hline $7^{\circ}$ & @midianinja & @petista_dsm & @midianinja & @)consuel60405976 \\
\hline $8^{\circ}$ & @samiabomfim & @midianinja & @)samiabomfim & @roberta57596546 \\
\hline $9^{\circ}$ & @1olaescreva & (a)cirogomes & @1olaescreva & @da_museu \\
\hline $10^{\circ}$ & @cirogomes & @samiabomfim & @cirogomes & $@$ malu_medeiro \\
\hline
\end{tabular}

Fonte: Autores da pesquisa. 
A terceira e última etapa da análise se refere à análise dos dados coletados a partir da hashtag \#Bolsonaro100mil, empregada nos tweets dos críticos ao governo Bolsonaro, conforme já exploramos na primeira análise. Na Tabela 03, observamos a prevalência do perfil de Reinaldo Azevedo como o principal articulador da rede no período da coleta de dados, cujo grau de entrada foi de 341, ou seja, a quantidade de conexões (menções, retweets, citações) recebidas pelo jornalista que atua no UOL Notícias, Folha de S. Paulo e Rádio Band News FM. Reinaldo Azevedo tem mais de 870 mil seguidores no Twitter e é uma figura controversa na condição de comentarista, havendo, inclusive, uma página no Wikipedia intitulada "críticas e controvérsias envolvendo Reinaldo Azevedo". Ele foi quem cunhou o termo pejorativo "petralha" (AZEVEDO, 2016), embora atualmente também seja um dos principais críticos ao governo de Jair Bolsonaro.

O deputado federal Marcelo Freixo, já apresentado na primeira análise, situa-se como importante ator na rede, principalmente pelas 82 conexões que recebeu no período e também por se relacionar na rede com outros nós relevantes. O perfil @ alexaguiarpoa, de Alexandre Aguiar, colunista do Jornal $\mathrm{NH}^{7}$ foi o terceiro com maior indegree e está entre os três nós mais importantes da rede, como pode ser visto nas colunas PageRank e Eigenvector. O colunista tem mais de 35 mil seguidores no Twitter e divulga conteúdos contrários à política de direita e extrema direita, defende a liberdade de imprensa e a democracia. É possível observar, ainda, a predominância de deputados e ex-deputados defensores de pautas mais progressistas e da Mídia Ninja, que também já mencionamos anteriormente.

A rede também se mostra muito coesa, pois aqueles que utilizaram a hashtag \#Bolsonaro100mil não divergem de opinião entre si (ou pouco divergem) na manifestação do dia 08 de agosto de 2020. Os clusters formados não divergem sobremaneira nas formas de pensar a política de gestão de Jair Bolsonaro no combate à COVID-19, no Brasil. Assim, as pontes entre as comunidades formadas não se davam entre posicionamentos diferentes. De toda forma, o perfil de @lolaescreva foi um dos principais articuladores entre os módulos, como forma de diálogo entre aqueles que também concordavam com as pautas defendidas por este nó.

\footnotetext{
${ }^{7}$ Jornal NH, que faz parte do Grupo Sinos, iniciou as atividades em 1960, em Nova Hamburgo (GRUPO SINOS, s.d.).
} 
Figura 06 - Grafo da hashtag \#Bolsonaro100Mil no Twitter 20h25-21h25 (08/08/20)

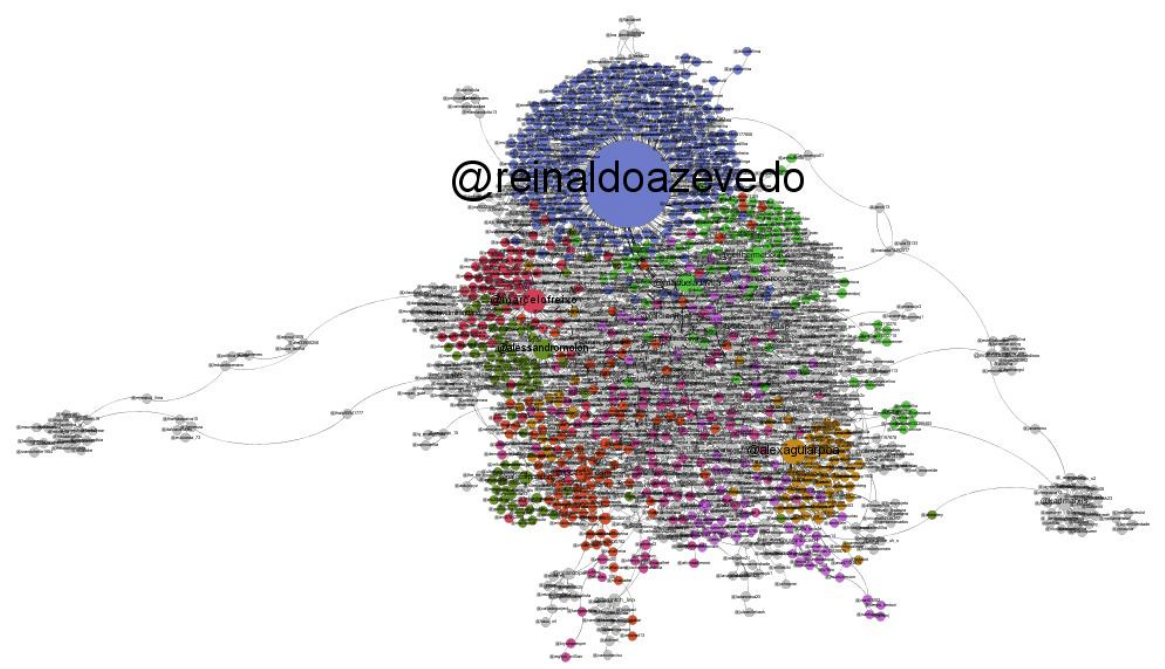

Fonte: Autores da pesquisa.

Embora não seja possível observar com nitidez os outros nós relevantes na rede, além de Reinaldo Azevedo, em azul (Figura 06), salientamos que o cluster de cor vermelha foi formado sobretudo pelas conexões intensas com o perfil de Marcelo freixo, e o de cor laranja, pelas conexões com o perfil do colunista Alexandre Aguiar. Neste caso, percebemos que não há um veículo de imprensa com grande expressividade na rede, contudo, dois profissionais da comunicação que exercem suas atividades em jornais.

\section{Considerações finais}

Os resultados mostram que poucos influenciadores digitais da rede são referências no jornalismo, tanto em termos de profissionais com formação em Comunicação como na baixa participação de grandes corporações de mídia nos fluxos comunicacionais que circulam no Twitter. Também observamos inexpressividade de influenciadores com autoridade para discutir ciência, mesmo que a temática do debate envolva uma discussão científica. Em grande medida, a politização da pandemia refletiu de forma acentuada na formação das redes nas mídias sociais, como percebemos pelas formações de clusters ao redor de políticos favoráveis ou contrários ao governo de Jair Bolsonaro. Os grafos são representações que nos levam ao debate sobre a circulação dos discursos polarizados entre bolhas, com conteúdos que pouco contribuem para a formação mais crítica de uma discussão que promova ações de enfrentamento à COVID-19. As pontes entre clusters geralmente são diálogos entre pares ou discussões pouco produtivas no sentido de produção de conhecimento. 
De forma geral, observamos que muitas "bolhas" vêm se formando no país (FELICIANO; CASTANHEIRA; SILVA, 2020; PARISER, 2011) e podem ser visualizadas nas redes formadas entre os interlocutores das mídias sociais, por exemplo, no grafo que analisamos anteriormente. Embora pensemos que a polarização tenha começado com o advento da internet, Perosa (2017) esclarece que diversos estudos na psicologia cognitiva revelam que o poder da crença - inclusive de afinidades políticas - dos sujeitos domina uma argumentação racional, mesmo antes do desenvolvimento das tecnologias digitais. Com isto, tem sempre uma tendência da confirmação de visões particulares, mesmo que entre em conflito aos fatos comprovados, discussão que vai ao encontro dos estudos de Festinger (1957). Sob esta perspectiva, mesmo com os estudos que mostram a ineficácia do medicamento Hidroxicloroquina para a cura do indivíduo com COVID-19, há uma expressividade de pessoas que preferem confirmar seu posicionamento particular.

Evidencia-se, assim, que a esfera pública se tornou um ambiente mais social que político na era moderna "ao mesmo tempo em que o social privatiza o público, principalmente o que concerne à garantia da sobrevivência, função realizada pelo trabalho" (DI FELICE, 2012) e percebemos isto de maneira mais clara ao responder "o que está sendo produzido aqui” e "o que está acontecendo aqui”. Observamos que os tweets servem como um reforço ao posicionamento do usuário, sem problematizar ou aprofundar aquilo que se acredita. Nesse sentido, constituem-se como laços fracos enquanto ação social, pois não operam na lógica de uma razão comunicativa (HABERMAS, 1984), mas, sim, como câmaras de eco (SUNSTEIN, 2001).

Este entendimento privativo da ação social na esfera pública pode ser equiparado à imagem da família. "A política associa-se à imagem da 'família', corpos políticos associados aos laços familiares trazendo a própria ruína da política que passa a operar uma série de funções para a reprodução do corpo social" (DI FELICE, 2012, p. 39). Assim, as fragmentações das opiniões públicas em meio a uma quantidade significativa de informações não agregam a diferença como princípio de reflexão na busca do consenso, pelo contrário, ecoam as semelhanças e o individualismo nocivos à manutenção do estado democrático e da formação de usuários-cidadãos. 


\section{Referências}

AS AÇÕES da OMS no combate à pandemia de coronavírus. Estado de Minas, 15 abr. 2020. Editoria Internacional, texto da AFP. Disponível em: https://www.em.com.br/app/noticia/internacional/2020/04/15/interna_internacional,1138765/a s-acoes-da-oms-no-combate-a-pandemia-de-coronavirus.shtml. Acesso em: 7 set. 2020.

AZEVEDO, Reinaldo. 15 anos depois de criada a palavra, os petralhas estão no olho da rua. Veja, 31 ago. 2016. Disponível em: https://veja.abril.com.br/blog/reinaldo/15-anos-depois-decriada-a-palavra-os-petralhas-estao-no-olho-da-rua/. Acesso em: 25 ago. 2020.

BASTOS, Marco Toledo. Public opinion revisited: the propagation of opinions in digital networks. Journal of Arab \&Muslim Media Research, v. 4, n. 2-3, p. 185-201, Mar. 2012. Disponível https://www.researchgate.net/publication/258176596_Public_Opinion_Revisited_The_propag ation_of_opinions_in_digital_networks. Acesso em: 25 ago. 2020.

BBC Brasil nasceu em 1938 com notícia sobre Hitler. BBC News Brasil, 20 jan. 2009, atualizado em 26 abr. 2011. Disponível em:

https://www.bbc.com/portuguese/institutional/090120_expediente_tc2.shtml. Acesso em: 25 ago. 2020.

BLUMLER, Jay G.; KATZ, Elihu. The uses of mass communication: current perspectives on gratifications research. Beverly Hills: Sage Publications, 1974.

BONACICH, Phillip. Power and centrality: a family of measures. American Journal of Sociology, v. 92, n. 5, p. 1170-1182, Mar. 1987. Disponível em: https://www.journals.uchicago.edu/doi/abs/10.1086/228631. Acesso em: 25/08/2020

BRAGA, José Luiz. Circuitos versus campos sociais. In: BRAGA, José Luiz. Mediação \& Midiatização. JANOTI JUNIOR, Jeder; MATOS, Maria Ângela; JACKS, Nilda (org,). Salvador: Edufba; Brasília: Compós, 2012. p. 31-52.

BRASIL chega aos 100 mil mortos por Covid; aplicativo dimensiona devastação da doença. G1, 08 de agosto de 2020. Disponível em: https://g1.globo.com/fantastico/noticia/2020/08/09/brasil-chega-aos-100-mil-mortos-porcovid-aplicativo-dimensiona-devastacao-da-doenca.ghtml. Acesso em 30 mar. 2021.

BRASIL é segundo no ranking mundial por COVID-19, diz OMS. UOL, 08 de ago. 2020. Disponível em https://www.bol.uol.com.br/noticias/2020/08/08/coronavirus-balanco-da-omsregistra-716075-mortes-e-19187943-casos-no-mundo.htm. Acesso em: 20 ago. 2020.

CASTELLS, Manuel. O poder da identidade. São Paulo: Paz e Terra, 2002b. (A era da informação: economia, sociedade e cultura, v. 2).

CASTELLS, Manuel. A sociedade em rede. São Paulo: Paz e Terra, 2002a. (A era da informação: economia, sociedade e cultura, v. 1). 
CORONAVÍRUS BRASIL. Painel Coronavírus. Ministério da Saúde, disponível em: https://covid.saude.gov.br/. Acesso em: 20 ago. 2020.

CRÍTICAS e controvérsias envolvendo Reinaldo Azevedo. Wikipédia. [S.d.]. Disponível em: https://pt.wikipedia.org/wiki/Cr\%C3\%ADticas_e_controv\%C3\%A9rsias_envolvendo_Reinal do_Azevedo. Acesso em: 15/ ago. 2020.

DI FELICE, Massimo. Netativismo: novos aspectos da opinião pública em contextos digitais. Revista FAMECOS: mídia, cultura e tecnologia, v. 19, n. 1, p. 27-45, 25 maio 2012. Disponível em: https://revistaseletronicas.pucrs.br/ojs/index.php/revistafamecos/article/view/11339. Acesso em: 29 ago. 2020.

FELICIANO, Luiz Antonio; CASTANHEIRA, Karol Natasha Lourenço; SILVA, Priscila Kalinke da. Profissionais especializados e receptores-fontes: a fotografia no contexto da 'pósverdade'. Comunicação Pública [online], v.15, n. 28,2020. Disponível em: http://journals.openedition.org/cp/7096. Acesso em: 26 ago. 2020.

FESTINGER, Leon. A theory of cognitive dissonance. Stanford: Stanford University Press, 1957.

GRUPO SINOS. História. [S.d.]. Disponível em: https://gruposinos.com.br/. Acesso em: 25 ago. 2020 .

HABERMAS, Jürgen. Direito e democracia. Rio de Janeiro: Tempo Brasileiro, 1997. v. 2.

HABERMAS, Jürgen. Mudança estrutural da esfera pública. Rio de Janeiro: Tempo Brasileiro, 1984.

HALL, Stuart. Da diáspora: identidades e mediações culturais. Brasília: Editora UFMG, 2006.

WHO Director-General's opening remarks at the media briefing on COVID-19. OMS, 11 de março de 2020. Disponível em: https://www.who.int/director-general/speeches/detail/whodirector-general-s-opening-remarks-at-the-media-briefing-on-covid-19---11-march-2020.

Acesso em: 30 mar. 2021.

INVESTIGADO pelo STF, blogueiro Allan dos Santos foge do Brasil. Catraca Livre, 31 jul. 2020. Disponível em: https://catracalivre.com.br/cidadania/investigado-pelo-stf-blogueiroallan-dos-santos-foge-do-brasil/. Acesso em: 25 ago. 2020.

JENKINS, Henry. Convergência e conexão são o que impulsiona a mídia agora. [Entrevista cedida a] Priscila Kalinke; Anderson Rocha. Revista Intercom, São Paulo, v. 39, n. 1, p. 213-219, jan./abr. 2016. Disponível em:

http://portcom.intercom.org.br/revistas/index.php/revistaintercom/article/view/2363. Acesso em: 10 ago. 2020. 
JENKINS, Henry. Cultura da convergência. São Paulo: Aleph, 2009.

JENKINS, Henry; GREEN, Joshua; FORD, Sam. Cultura da conexão: criando valor e significado por meio da mídia propagável. São Paulo: Editora Aleph, 2014.

LASSWELL, Harold. A estrutura e a função da comunicação na sociedade. In: COHN, Gabriel. Comunicação e indústria cultural. São Paulo: TA Queiroz, 1987. p. 105-117. [Texto original publicado em 1948.]

LAZARSFELD, Paul; MERTON, Robert. Comunicação de massa, gosto popular e ação social organizada (1948). In: COHN, Gabriel. Comunicação e indústria cultural. São Paulo: TA Queiroz, 1987. p.230-253. Texto original publicado em 1948.

MARTÍN-BARBERO, Jesús. Dos meios às mediações: comunicação, cultura e hegemonia. Rio de Janeiro: UFRJ, 1997.

MÍDIA NINJA. Quem somos. [S.d.] Disponível em: https://midianinja.org/quem-somos/. Acesso em: 25 ago. 2020.

MORALES, James Edward Humberston; ALENS, Fernando José Alvarez. A. Análisis de redes sociales: identificación de comunidades virtuales en Twitter. Realidad y Reflexión, San Salvador, año 19, n. 50, 2019.

PARISER, Eli. The filter bubble. New York: The Penguin Press, 2011.

PEROSA, Teresa. O império da pós-verdade. Época, 25 abr. 2017, atualizado em 26 abr. 2017. Disponível em: https://epoca.globo.com/mundo/noticia/2017/04/o-imperio-da-posverdade.html. Acesso em: 25 ago. 2020.

PINTO, Ana Estela de Sousa. América Latina é o epicentro da pandemia, e Brasil é o país mais preocupante, diz OMS. Folha de S. Paulo, maio 2020. Disponível em: https://www1.folha.uol.com.br/equilibrioesaude/2020/05/america-latina-e-o-epicentro-dapandemia-e-brasil-e-pais-mais-preocupante-diz-oms.shtml. Acesso em: 30 mar. 2021.

RECUERO, Raquel. Contribuições da Análise de Redes Sociais para o estudo das redes sociais na Internet: o caso da hashtag \#Tamojuntodilma e \#CalaabocaDilma. Fronteiras estudos midiáticos, v. 16, n. 2, p. 60-77, 2014. Disponível em:

http://revistas.unisinos.br/index.php/fronteiras/article/view/fem.2014.162.01. Acesso em: $25 / 08 / 2020$

RECUERO, Raquel. Redes sociais na Internet. Porto Alegre: Sulina, 2009.

RECUERO, Raquel; BASTOS, Marco; ZAGO, Gabriela. Análise de redes para mídia social. Porto Alegre: Sulina, 2018.

RECUERO, Raquel; ZAGO, Gabriela; SOARES, Felipe Bonow. Midia social e filtros-bolha nas conversações políticas no Twitter. ENCONTRO ANUAL DA COMPÓS, 26., 2017, São Paulo. Anais [...]. São Paulo: Cásper Líbero, 2017. Disponível em: 
https://lume.ufrgs.br/handle/10183/166193. Acesso em: 20 ago. 2020.

SUNSTEIN, Cass. Echo chambers. Princeton: Princeton University Press, 2001.

THOMAZ, Danilo. Grupo paulista de direita cria movimento conservador para atuação nacional. Época, 06 ago. 2019, atualizado em 16 nov. 2019. Disponível em: https://epoca.globo.com/brasil/grupo-paulista-de-direita-cria-movimento-conservador-paraatuacao-nacional-23856855. Acesso em: 25 ago. 2020.

VEÍCULOS de comunicação formam parceria para dar transparência a dados de Covid-19. G1, 8 jun. 2020. Política. Disponível em:

https://g1.globo.com/politica/noticia/2020/06/08/veiculos-de-comunicacao-formam-parceriapara-dar-transparencia-a-dados-de-covid-19.ghtml. Acesso em: 7 set. 2020.

Submetido em 11.09. 2020

Aprovado em 08.12.2020 